\title{
Proteomic survey towards the tissue-specific proteins of mouse mitochondria
}

\author{
WANG Yuan, SUN HaiDan, RU YaWei, YIN SongYue, YIN Liang \& LIU SiQi* \\ Beijing Institute of Genomics, Chinese Academy of Sciences, Beijing 101300, China
}

Received June 29, 2010; accepted July 30, 2010

\begin{abstract}
Mitochondrion plays the key functions in mammalian cells. It is believed that mitochondrion exerts the common biologic functions in many tissues, but also performs some specific functions correspondent with tissues where it is localized. To identify the tissue-specific mitochondrial proteins, we carried out a systematic survey towards mitochondrial proteins in the tissues of C57BL/6J mouse, such as liver, kidney and heart. The mitochondrial proteins were separated by 2DE and identified by MALDI-TOF/TOF MS. Total of 87 unique proteins were identified as the tissue-specific ones, and some representatives were further verified through ICPL quantification and Western blot. Because these issue-specific proteins are coded from nuclear genes, real-time PCR was employed to examine the mRNA status of six typical genes found in the tissues. With combining of the expression data and the co-localization images obtained from confocal microscope, we came to the conclusion that the tissue-specifically mitochondrial proteins were widely distributed among the mouse tissues. Our investigation, therefore, indeed provides a solid base to further explore the biological significance of the mitochondrial proteins with tissue-orientation.
\end{abstract}

proteomics, tissue-specific, mitochondria

Citation: Wang Y, Sun H D, Ru Y W, et al. Proteomic survey towards the tissue-specific proteins of mouse mitochondria. Sci China Life Sci, 2011, 54: 3-15, doi: 10.1007/s11427-010-4107-0

In eukaryotic cells, mitochondria oxidize organic acids via the tricarboxylic acid cycle and ATP synthesis as primary functions. Mitochondria also have several pivotal roles for the maintenance of physiological activities, such as the generation of reactive oxygen species, calcium metabolism and apoptosis [1,2]. Mitochondrial dysfunction is linked to a wide range of human diseases, such as neurodegeneration, diabetes, metabolic disorders, tumorigenesis and myopathies $[3,4]$. Mitochondrion is a unique organelle and has its own genome (mitochondrial DNA, mtDNA), encoding 13 essential proteins constituting complexes I, III, IV and V of the oxidative phosphorylation system [5]. Approximately 3000 proteins are estimated to be present in mitochondria, clearly indicating that many of these proteins are nuclear-encoded and transported into the organelle from extra-mitochondrial

*Corresponding author (email: siqiliu@genomics.org.cn) sources [6].

Mitochondria in different tissues vary in number, morphology, ultrastructure, respiratory capacity and specific metabolic pathways [6]. Most nucleated cells contain 500 to 2000 mitochondria. For instance, mitochondria make up $80 \%$ of the intracellular volume of the cone cells of eyes, $60 \%$ in the lateral rectus cells and $40 \%$ in heart muscle cells. In contrast, platelets have only two to six mitochondria per cell [7]. A living species genome is relatively stable during the life span of the organism, whereas its gene expression profiles vary dramatically and are tissue dependent $[8,9]$. Since mitochondrial number is tissue-dependant and most their proteins rely on the gene expression status in the resided tissues, a question thus is raised whether a mitochondrion in a tissue owns its specific proteome.

Tissue-specific mitochondrial proteins drew much attention in the 1980s. Vayssiere et al. [10] adopted 2D electro- 
phoresis (2DE) to separate the mitochondrial proteins from the rat brain cortex, muscle and liver, and found the $2 \mathrm{DE}$ spots distribution was dependent on tissue localization. In particular, 16 2DE spots were found exclusively in brain mitochondria. Watmough et al. [11] compared mitochondrial proteins between normal patients and patients with weak muscles, and reported that the abundance of the complex I protein had decreased in the muscles of patients that were weak; however no change was observed for the protein distribution between the two groups for mitochondrial proteins isolated from the liver. These early investigations did not provide enough information to identify the tissue-specific proteins in mitochondria because of the limited analytical approaches. Since the turn of the century, proteomic approaches have expedited protein research, including the identification of proteins present in various tissues and organelles [12]. Using shotgun tryptic-digestion and LC MS/MS, Mann's group screened mitochondrial proteins obtained from the mouse brain, heart, kidney and liver [13]. In total, 399 mitochondrial proteins were identified, in which approximately $50 \%$ were not generally detected in all the tissues. This group implemented a quantitative proteomics approach to compare the mitochondrial proteins extracted from the rat tissues, heart, liver and skeletal muscle, and observed that approximate one third of the mitochondrial proteins identified were predominant to one of the three tissues [14]. The largest scale screening for the tissue-specific proteins of cytosol, microsomes, mitochondria and nuclei in the mouse brain, heart, kidney, liver, lung and placenta was performed using a gel-free multidimensional protein identification technology developed by Kislinger $e t$ $a l$. [15]. Using rigorous statistical filtering and machinelearning methods, the subcellular localization of 3274 of the 4768 proteins identified was determined, including 1503 previously uncharacterized factors. Proteomics provides insight into the tissue-specific expression of mitochondrial proteins. However, several issues have not been addressed, such as the elucidation of tissue-specific mitochondrial proteins. The survey of mitochondrial proteins in early investigations was based upon LC MS/MS. These studies presented solid data for peptide separation as well as identification; however, evidence for intact protein separation as well as identification was missing. Protein identification and localization must proceed through a systematic approach and involve different approaches to examine cells and tissues. Early analysis of mitochondrial proteins also lacked a complete analysis approach.

Herein, we have extended a systematic survey of the mitochondrial proteomes in the mouse tissues of liver, kidney and heart with specific focus on the identification of intact proteins present in mitochondria and the quantification of the different mitochondrial proteomes from the mouse tissues. The mitochondrial proteins were separated by $2 \mathrm{DE}$ and identified by MALDI TOF/TOF MS. In total, 87 unique proteins were identified as tissue-specific proteins. Some mitochondrial proteins were further verified through isotope coded protein label (ICPL) quantification and Western blot analysis. Because these tissue-specific proteins were from nuclear encoded genes, we employed real-time PCR and Western blot analysis to examine the status of the distribution and abundance of six typical genes in the tissues. By combining the expression data and the co-localization images obtained from confocal microscopy, we concluded that mitochondrial proteins with tissue-specificity were widely distributed among the mouse tissues. Therefore, our investigation provides a set of data for exploring the biological significance of tissue-specific mitochondrial proteins.

\section{Materials and methods}

\subsection{Chemicals}

Acrylamide, ammonium persulfate, IPG strips ( $5 \mathrm{~mm} \times 180$ $\mathrm{mm}$ or $5 \mathrm{~mm} \times 70 \mathrm{~mm}, \mathrm{pH} 3-10$ linear), ampholyte $\mathrm{pH} 3-10$, urea, CHAPS and all ultrapure reagents for electrophoresis were obtained from Bio-Rad (Hercules, CA, USA). All chemicals were of analytical grade and were purchased from Sigma (St. Louis, MO). Modified porcine trypsin was from Promega (Madison, WI). The reagents for cell culturing were from Sigma (St. Louis, MO).

\subsection{Mitochondria preparation}

Six- to nine-weeks old C57BL6/J male mice were subjected to anesthesia by a phenobarbital celiac injection $\left(50 \mathrm{mg} \mathrm{kg}^{-1}\right.$, $10 \mathrm{mg} \mathrm{mL}^{-1}$ ) and then perfused with ice-cold saline. The tissues, liver, kidney and heart, were rapidly excised, immersed into ice-cold PBS buffer and weighed. The tissues were minced and homogenized with a hand-held Dounce homogenizer in the pre-cool homogenization buffer, $220 \mathrm{mmol} \mathrm{L}^{-1}$ mannitol, $70 \mathrm{mmol} \mathrm{L}^{-1}$ sucrose, $10 \mathrm{mmol} \mathrm{L}^{-1}$ Tris-HCl, $\mathrm{pH}$ 7.4, containing protease and phosphatase inhibitors. Using gradient centrifugation, the crude mitochondria were pelleted at $8000 \times g$. The crude preparation was further centrifuged through a Nycodenz density gradient from $20 \%$ to $34 \%$ at $52000 \times g$ for $1.5 \mathrm{~h}$. The refined mouse mitochondria were enriched upon density fractionation. The integrity and purity of the purified mitochondria were assessed by transmission electron microscopy (TEM) and western blot analysis using mitochondrial specific antibodies, ATP synthase $\beta$ (BD Biosciences, CA), prohibitin, aldehyde dehydrogenase II (Santa Cruz, CA) as well as antibodies directed against the cytoplasm and a cytoplasm specific antibody, aldehyde reductase and GAPDH, were purchased from Santa Cruz, CA. The purified mitochondria were stored at $-80^{\circ} \mathrm{C}$.

\section{$1.3 \quad 2 \mathrm{DE}$}

The harvested mitochondria were washed three times using 
washing buffer (50:50:0.1 volumes of ethanol:acetone: acetic acid) and subsequently lysed with lysis buffer containing $7 \mathrm{~mol} \mathrm{~L}^{-1}$ urea, $2 \mathrm{~mol} \mathrm{\textrm {L } ^ { - 1 }}$ thiourea, $4 \%(\mathrm{w} / \mathrm{v})$ CHAPS, $10 \mathrm{mmol} \mathrm{L}^{-1}$ DTT, $1 \mathrm{mmol} \mathrm{L}{ }^{-1}$ PMSF and $2 \mathrm{mmol}$ $\mathrm{L}^{-1}$ EDTA. The lysed mitochondria were sonicated with a probe sonicator for $5 \mathrm{~min}$ followed by centrifugation at $35000 \times g$ for $30 \mathrm{~min}$. After quantification of the proteins using the Lowry assay, the supernatants were used for electrophoresis. Approximate $100 \mu \mathrm{g}$ protein was loaded for 2DE analysis. Isoelectric focusing was carried out using 18 $\mathrm{cm}, \mathrm{pH} \mathrm{3-10} \mathrm{L} \mathrm{IPG} \mathrm{strips} \mathrm{and} \mathrm{run} \mathrm{at} 70 \mathrm{kVh}$ and 0.05 $\mathrm{mA} / \mathrm{strip}$ at room temperature. After reduction using $1 \%$ DTT for $15 \mathrm{~min}$ and alkylation using $2.5 \%$ IAM for $15 \mathrm{~min}$, the second-dimension SDS-PAGE was conducted in $18 \mathrm{~cm}$ $12 \%$ acrylamide gels at $15 \mathrm{~W} /$ gel until the dye front reached the bottom of the gels.

The 2DE gels were stained using silver nitrate with a modified protocol. All the silver-stained gels were scanned by a laser densitometer at 500 pixel resolution (Powerlook 2100XL, UMAX, Dallas, TX). The gel images were analyzed with Imagemaster Platinum version 5.0 (GE Healthcare, Fairfield, CT). The threshold defined as the significant change in spot volume was 3-fold at least upon the comparison of the average gels between liver, kidney and heart. The final spot volumes were statistically determined using three mitochondrial preparations as well as duplication runs.

\subsection{Protein identification with mass spectrometry}

The differential 2DE spots were manually excised and diced into small pieces $(<1 \mathrm{~mm})$. The proteins were digested with $0.025 \mathrm{mg} \mathrm{mL}^{-1}$ trypsin in $25 \mathrm{mmol} \mathrm{L}^{-1} \mathrm{NH}_{4} \mathrm{HCO}_{3}$ and incubated at $37^{\circ} \mathrm{C}$ for $16 \mathrm{~h}$. Only $1 \mu \mathrm{g}$ of the supernatant from the in-gel digestions was loaded onto the Anchorchip target (Bruker Dalton, Bremen, Germany) and allowed to dry completely. Then $0.8 \mu \mathrm{L}$ of the matrix solution (CHCA, $1: 1$, $\mathrm{v} / \mathrm{v}$ ) was added to the target and mixed with the digested peptides. After washing with $0.5 \%$ TCA, the Anchorchips were delivered to the MALDI TOF/TOF mass spectrometry (MS) for protein identification. Positively charged ions were analyzed in the reflector mode, using delayed extraction. Typically 100 shots were accumulated per spectrum in the MS mode and 400 shots in the MS/MS mode. The spectra were processed using the FlexAnalysis 2.2 and BioTools 2.2 software tools.

Based upon mass signals, protein identification was performed using the Mascot software (http://www.matrixscience.com) to search the NCBI's nr database using the mouse taxonomy. The following parameters were used for database searches: monoisotopic mass accuracy $<0.01 \%$, missed cleavages 1 , carbamidomethylation of cysteine as a fixed modification, oxidation of methionine, N-terminal pyroglutamylation (peptide) and $\mathrm{N}$-terminal acetylation (protein) as variable modifications. In the MS/MS mode, the fragment ion mass accuracy was set to $<0.7 \mathrm{Da}$.

\subsection{Quantitative proteomics using an ICPL}

The ICPL strategy was performed using the instruction manual from SERVA (SERVA Electrophoresis, Heidelberg, Germany). The protein samples were chemically derivatized to two distinguishable isotopic forms (light, nondeuterated, ${ }^{12} \mathrm{C}$ and heavy, deuterated, ${ }^{13} \mathrm{C}$ ). Equal aliquots of the two differentially labeled samples were mixed and separated by 2DE. Protein quantification was automatically calculated by the relative abundance of light and heavy ICPL-labeled peptides using the Peakpicker software (Applied Biosystems, USA).

\subsection{Western blot analysis}

Equal amount proteins (10 $\mu \mathrm{g} / \mathrm{lane})$ of each sample were loaded onto a $12 \%$ SDS-PAGE and electro-transferred to polyvinylidene difluoride (PVDF) membranes (350 mA, $1 \mathrm{~h}$ ) using a Bio-Rad Mini PROTEAN 3 system (Hercules, CA, USA) according to the standard protocol. The PVDF membranes were blocked with TBS containing 5\% nonfat milk powder and $0.1 \%$ Tween 20 at $4{ }^{\circ} \mathrm{C}$ overnight, and incubated with the individual antibodies as primary ones, such as anti-SCP2, anti-HADHB, anti-SCOT were generated from our laboratory by immunization of rabbits with the purified SCOT and HADHB recombinant protein, anti-aldehyde dehydrogenase II, anti-prohibitin, anti-aldehyde reductase, anti-catalase (The Binding Site Inc. USA), anti-PDZK 1, anti-sMtCK, anti-GAPDH (Santa Cruz Biotechonolgy, USA), and anti-ATP synthase $\beta$ (BD Biosciences, USA). The appropriate secondary antibody conjugated with horse radish peroxidase (HRP) was used to visualize the primary immune-recognitions using the ECL kit (Amersham Pharmacia Biotech, Uppsala, Sweden).

\subsection{Quantitative real-time RT-PCR}

Quantification of gene expression for SCP2, PDZK1, $s M t C K$, catalase, SCOT and $H A D H B$ was performed via real-time RT-PCR using an ABIPRISM 7300 system (Applied Biosystems, Foster City, CA). The cDNA libraries were generated from the total RNA preparations performed using the isolated mouse liver, kidney and heart tissues. The primers were designed to span the exon-intron junctions of these genes as follows, SCP2: 5'-TGCCTTCAAAGTGAAAGATGGCCC-3' (forward) and 5'-TTCCCTTGAAAGAAGGCCGACTGA-3' (reverse); PDZK1: 5'-AGGCAGCTGGCTTGAAGAACAATG-3' (forward) and 5'-AAAGAAGTGGAGAGAACCGAGCCA-3' (reverse); sMtCK: 5'TAAGATCTTGGAGAACCTGCGGCT-3' (forward) and 5'-TCTTGGCCTCTCTCCAGCTTCTTT-3' (reverse); catalase: 5'-TGCAGATACCTGTGAACTGTCCCT-3' (forward) and 5'-AAGCGTTTCACATCTACAGCGCAC-3' (reverse); 
SCOT: 5'-GCTCTGGTGAAAGCATGGAAAGCA-3' (forward) and 5'-TCCCTTTATGAGGCGGTGCACATA-3' (reverse); HADHB: 5'-CACTTTCGGGTTTGTTGCATCGGA$3^{\prime}$ (forward) and 5'-GCTGTGGTCATGGCTTGGTTTGAA-3' (reverse).

Each sample was normalized on the basis of GAPDH expression. Data were analyzed according to the relative gene expression using the $2^{-\Delta \Delta \mathrm{Ct}}$ method. Moreover, melting curves for each PCR reaction were analyzed carefully to confirm the purity of the amplification product.

\subsection{Confocal experiments}

Three cell lines derived from normal tissues were adopted for the confocal experiments: the Chang cell line for the liver (a gift from Dr. Liu YinKun, Fudan University), the MC cell line for the kidney (a gift from Dr. Guan YouFei, Peking University) and the $\mathrm{H} 9 \mathrm{C} 2$ cell line for the heart (ATCC, Rockville, MD). The three cell lines were seeded into humidified chambers and cultured for $24 \mathrm{~h}$. Subsequently, the cells were incubated with diluted MitoTracker Red (Invitrogen, Eugene, USA) for 30 min and fixed with $3.7 \%$ formaldehyde for $15 \mathrm{~min}$. The antibodies against specific proteins were used as the primary antibodies and incubated with the fixed cells for $2 \mathrm{~h}$. Following thorough washing of the material with $0.05 \%$ Triton X-100 in PBS, the treated cells were incubated with the FITC-conjugated goat immunoglobulins against rabbit IgG contained in $1 \%$ BSA PBS for $1 \mathrm{~h}$. The fluorescent images were acquired using a confocal laser scanning microscope, Zeiss LSM510 (Carl Zeiss MicroImaging, Aalen, Germany). For referencing organelle localization, DAPI was used to stain the nuclei.

\section{Results}

\subsection{Analysis of 2DE images from the mitochondria of different mouse tissues}

To ensure the quality of mitochondrial preparation from mouse tissues, the prepared mitochondria were examined by western blot and TEM analyses. With three specific antibodies against mitochondrial proteins in the western blot analysis, ATP synthase $\beta$, aldehyde dehydrogenase II and Prohibitin, the unique immuno-recognized bands appeared in the three preparations of mitochondria; however, these bands were not observed in the cytoplasm fractions (Supplemental Figure 1A). The TEM images for the mitochondrial preparations revealed that the ratios of intact mitochondria were $>90 \%$ (Supplemental Figure 1B). The mitochondrial proteins were resolved by $2 \mathrm{DE}$ as shown in Figure $1 \mathrm{~A}$. To avoid experimental errors generated by $2 \mathrm{DE}$ operations and individual variations among mice, the mitochondria were individually prepared from six mice, and each mitochondrial preparation was duplicated in the 2DE analysis. For each tissue, the 2DE images were statistically analyzed on the basis of the six samples. On average, there were $754 \pm 35(n=6) 2 \mathrm{DE}$ spots identified for the heart mitochondria, $1018 \pm 47(n=6) 2 \mathrm{DE}$ spots were identified for the kidney mitochondria and $1039 \pm 46(n=6) 2 \mathrm{DE}$ spots were identified for the liver analysis. The overlapping rates of the 2DE spots for the parallel preparations and runs were approximate $90 \%$. As shown in Figure 1A, the 2DE patterns are clearly different between the individual tissues. The total number of $2 \mathrm{DE}$ spots from the heart mitochondria samples was almost $30 \%$ less than the other two tissues. The number of $2 \mathrm{DE}$ spots located within the higher $\mathrm{pI}$ side for the heart mitochondria were significantly more than that of the mitochondrial proteins observed for both the liver and kidney samples. Moreover, mouse liver and kidney mitochondria were comparable with overlapping rates of approximately $80 \%$. To identify $2 \mathrm{DE}$ spots specifically located in a certain mitochondrial preparation, comparison of the 2DE images was initially conducted between any two tissue mitochondria, i.e., liver vs. heart, heart vs. kidney and kidney vs. liver, and then these spots with infinite change in spot volume were further confirmed by comparison with the third tissue. A total of 134 tissue-specific 2DE spots were defined; 26 as liver specific, 18 as kidney specific and 10 as heart specific. Moreover, $62 \mathrm{DE}$ spots were identified in both heart and liver but not in kidney, 19 were shared with heart and kidney but not in liver, and 55 were shared with liver and kidney but were not observed for the heart samples. The localized comparison of 2DE images for several tissue specific spots is presented in Figure 1B.

\subsection{Identification of tissue-specific mitochondrial pro- teins by MALDI TOF/TOF MS}

The 134 different 2DE spots were in-gel tryptic digested and delivered to MALDI-TOF/TOF MS. Of the 87 spots identified as proteins, 20 were liver specific, such as SCP2, 14 were kidney specific, such as PDZK1, and six were heart specific, such as sMtCK. Five proteins were shared by heart and liver, but not by kidney such as HADHB, eight were shared by heart and kidney but not by liver, such as SCOT, and 34 were shared by liver and kidney but not by heart, such as catalase. Figure 1C shows a typical MALDI-TOF/ TOF mass spectrogram, indicating that PDZK1 is present. The identification summary based upon mass spectrometry analysis is presented in Table 1 .

According to the Gene Ontology (GO) analysis, the 87 identified proteins were divided into five categories based on biological functions. Of these proteins, 24 were related with energy metabolism, eight with apoptosis, 17 with maintenance of ionic homeostasis, 28 with oxidative phosphorylation, and 10 with other functions. Basing the GO analysis on subcellular locations, 52 proteins were predicted as mitochondrial located, seven as part of an endomembrane system 

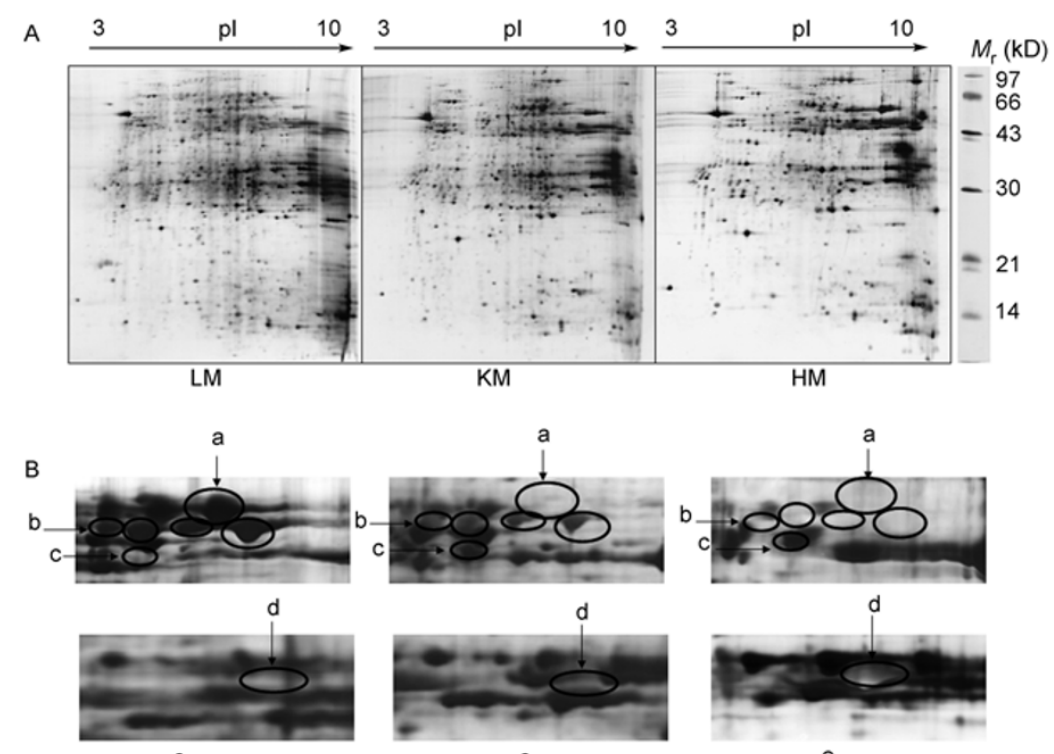

d

d
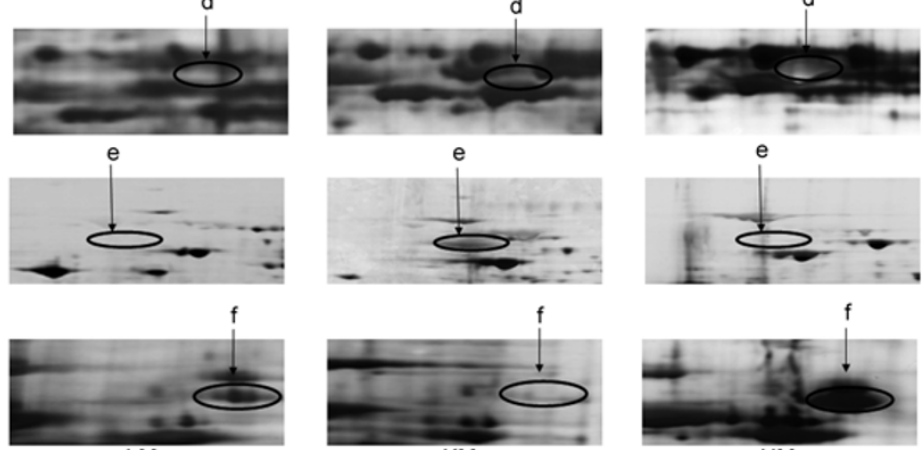

f
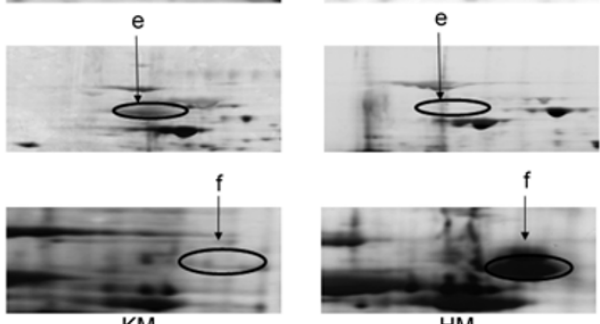

$\mathrm{KM}$

$\mathrm{HM}$

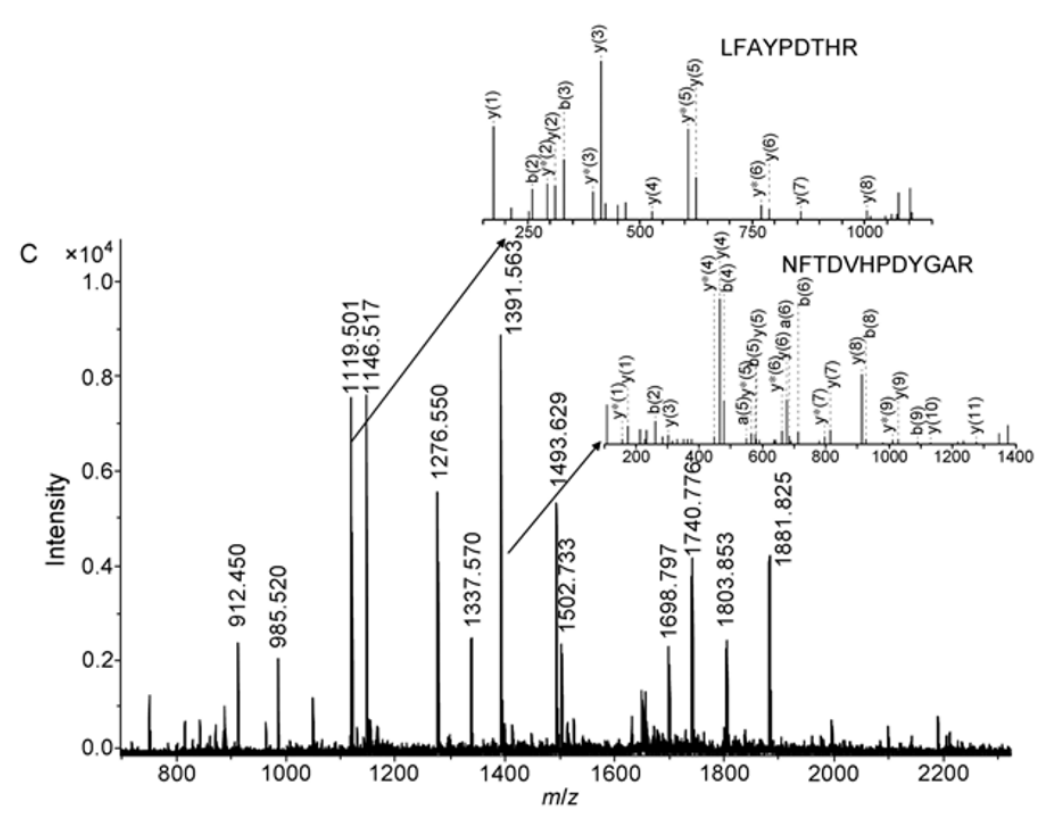

Figure 1 2DE images of the mitochondrial proteins from mouse liver, kidney and heart and the protein identification by MALDI TOF/TOF MS. A, The 2DE images of the mitochondrial proteins extracted from mouse liver (LM), kidney (KM) and heart (HM). B, The typically close-up analysis of the 2DE images for the tissue-specific spots. Spots labeled with a, d, and e were specific to liver, heart and kidney, respectively. The spot labeled with $b$ is shared by liver and kidney but was not observed in heart samples; the spot labeled $\mathrm{c}$ is shared by kidney and heart not by the liver; the spot marked $\mathrm{f}$ was found in the liver and heart samples but was not observed in the kidney samples. C, The spectra of MALDI TOF/TOF MS and MS/MS for the identification of PDZK1. Upon the PMF signals, the parent ions 1119.501 and 1391.563 were selected for MS/MS analysis, which led to two peptides with amino acid sequences derived from the sequence of PDZK1 as LFAYPDTHR and NFTDVHPDYGAR.

(including endoplasmic reticulum, peroxisome, and microsome) and 28 were non-specific subcellular localized. Of the 87 unique tissue-specific mitochondrial proteins in our list, 12 are also documented in the report by Mann. 
Table 1 Identification of the tissue-specific 2DE Spots by MALDI-TOF/TOF MS

\begin{tabular}{|c|c|c|c|c|c|c|}
\hline $\begin{array}{l}\text { Spot } \\
\text { No. }\end{array}$ & $\begin{array}{l}\text { Swiss-port } \\
\text { number }\end{array}$ & Protein name & $\begin{array}{c}\text { Mass } \\
\text { Cal./Obs. }\end{array}$ & $\begin{array}{c}\text { pI } \\
\text { Cal./Obs. }\end{array}$ & $\begin{array}{l}\text { Sequence } \\
\text { coverage } \\
(\%)\end{array}$ & MS/MS \\
\hline \multicolumn{7}{|c|}{ Liver-specific mitochondrial proteins } \\
\hline 2 & gi|6754156 & Hydroxyacid oxidase 1 , liver & $41260 / 42467$ & $7.60 / 7.92$ & 63 & NVADIDLSTSVLGQR \\
\hline 3 & gi|477004 & Epoxide hydrolase & $63117 / 62399$ & $5.85 / 6.23$ & 72 & YQIPALAQAGFR \\
\hline 4 & gi|74200069 & Calregulin & $42341 / 64342$ & $4.57 / 6.21$ & 70 & $\begin{array}{l}\text { IKDPDAAKPEDWDER } \\
\text { ILFIFIDSDHTDNQR }\end{array}$ \\
\hline 5 & gi|127526 & Major urinary protein 1 precursor & $20920 / 20587$ & $5.02 / 4.52$ & 48 & \\
\hline 6 & gi|18044669 & Urate oxidase & $35245 / 35482$ & $8.48 / 8.32$ & 32 & AHVYVEEVPWKR \\
\hline 7 & gi|6678085 & Serine proteinase inhibitor & $46140 / 51913$ & $5.24 / 5.30$ & 23 & \\
\hline 8 & gi|23396871 & Small ubiquitin-related modifier3 & $12593 / 53764$ & $5.25 / 5.39$ & 35 & \\
\hline 9 & gi|18044557 & Peroxiredoxin 4 & $31261 / 29939$ & $6.57 / 6.28$ & 48 & \\
\hline 10 & gi|13879360 & Cathepsin B precursor & $38168 / 26073$ & $5.57 / 5.27$ & 27 & SGVYKHEAGDMMGGHAIR \\
\hline 11 & gi|47682713 & Nudix-type motif 7 & $27068 / 31324$ & $5.90 / 6.16$ & 16 & FGLGPEPPR \\
\hline 12 & gi|30354044 & Insulin-like growth factor 2 & $63681 / 23537$ & $9.31 / 5.84$ & 10 & \\
\hline 13 & gi|50299 & Cathepsin D & $44742 / 31129$ & $6.71 / 5.92$ & 23 & $\begin{array}{l}\text { NYELHPDKYILK } \\
\text { NIFSFYLNR }\end{array}$ \\
\hline 14 & gi|2624496 & Glutathione S-transferase P 1 & $23521 / 24501$ & $8.13 / 7.76$ & 36 & $\begin{array}{c}\text { PPYTIVYFPVR } \\
\text { FEDGDLTLYQSNAILR }\end{array}$ \\
\hline 15 & gi|226471 & Superoxide dismutase $[\mathrm{Cu}-\mathrm{Zn}]$ & $15923 / 17653$ & $9.03 / 6.31$ & 43 & \\
\hline 16 & gi|19353248 & Hydroxymethylgulataryl-CoA synthase & $57300 / 49579$ & $8.65 / 7.93$ & 30 & TKLPWDAVGR \\
\hline 17 & gi|33859506 & Albumin 1 & $70730 / 75458$ & $5.75 / 5.75-6.02$ & 37 & LGEYGFQNAILVR \\
\hline 18 & gi|56789381 & Acidic ribosomal phosphoprotein $\mathrm{P} 0$ & $34366 / 36764$ & $5.91 / 5.87$ & 65 & \\
\hline 19 & gi|13384700 & Endoplasmic reticulum protein ERp19 & $19208 / 19577$ & $5.14 / 5.10$ & 47 & \\
\hline 20 & gi|193446 & Vitamin D-binding protein & $54647 / 56333$ & $5.62 / 5.17$ & 35 & $\begin{array}{c}\text { SLSLILYSR } \\
\text { RTQVPEVFLSK }\end{array}$ \\
\hline \multicolumn{7}{|c|}{ Kidney-specific mitochondrial proteins } \\
\hline 21 & gi|32363497 & Cytovillin & $69347 / 70826$ & $6.28 / 6.31$ & 35 & \\
\hline 22 & gi|2827776 & Endopeptidase-2 & $85227 / 84967$ & $6.00 / 5.24-5.76$ & 23 & VGVYDKDCDCFR \\
\hline 24 & gi|5305216 & Glutathione peroxidase & $22553 / 24680$ & $6.54 / 5.98$ & 23 & \\
\hline 25 & gi|2494732 & Gamma-glutamyltranspeptidase 1 & $61866 / 24708$ & $7.00 / 6.81$ & 15 & $\begin{array}{l}\text { ASGGWAAASDSR } \\
\text { DIDQVVTAGLK }\end{array}$ \\
\hline 26 & gi|6755963 & Voltage-dependent anion channel 1 & $30891 / 34360$ & $9.00 / 7.96$ & 48 & LVAAKCTLAAR \\
\hline 27 & gi|2058343 & V-ATPase B2 subunit & $56948 / 58414$ & $6.00 / 5.38$ & 29 & \\
\hline 28 & gi|13626101 & Alpha-methylacyl-CoA racemase & $39854 / 40560$ & $7.00 / 7.61$ & 36 & \\
\hline 29 & gi|220396 & D-amino-acid oxidase & $38970 / 39636$ & $7.00 / 7.42$ & 41 & SYLPWLTER \\
\hline 30 & gi|125957 & Lamin B2 & $67103 / 68540$ & $7.32 / 7.60$ & 42 & \\
\hline 31 & gi|20336740 & Ret finger protein-like 4 & $33079 / 32203$ & $8.00 / 7.78$ & 20 & \\
\hline 32 & gi|3114602 & $\begin{array}{c}\text { Phospholipid hydroperoxide glutathione } \\
\text { peroxidase }\end{array}$ & $22794 / 19826$ & $8.74 / 8.28$ & 28 & \\
\hline 33 & gi|15617203 & Chloride intracellular channel 1 & $27338 / 30537$ & $5.09 / 4.97$ & 48 & \\
\hline 34 & gi|14874758 & Peroxiredoxin 2 & $21936 / 22347$ & $5.20 / 4.62$ & 32 & \\
\hline \multicolumn{7}{|c|}{ Heart-specific mitochondrial proteins } \\
\hline 35 & gi|38259206 & $\begin{array}{l}\text { Creatine kinase, mitochondrial } 2 \\
\text { (sMtCK) }\end{array}$ & $47899 / 45112$ & $8.64 / 8.25$ & 59 & ITHGQFDER \\
\hline 36 & gi|18700024 & Isocitrate dehydrogenase 3 & $42453 / 41763$ & $8.76 / 7.33$ & 46 & HNNLDLVIIR \\
\hline 37 & gi|33563264 & Myosin, light polypeptide 3 & $23 / 26330$ & $5.03 / 5.09$ & 50 & $\begin{array}{l}\text { ITYGQCGDVLR } \\
\text { ALGQNPTQAEVLR }\end{array}$ \\
\hline 38 & gi|38605043 & $\begin{array}{l}\text { Myosin regulatory light chain } 2, \text { ven- } \\
\text { tricular/cardiac muscle isoform }\end{array}$ & $18870 / 19893$ & $4.71 / 4.76$ & 81 & DGFIDKNDLR \\
\hline 39 & gi|3806019 & Ubiquinone biosynthesis protein coq7 & $20228 / 19893$ & $5.52 / 6.04$ & 27 & \\
\hline 40 & gi|160151263 & $\begin{array}{l}\text { Dihydrolipoyllysine-residue succinyl- } \\
\text { transferase component of } \\
\text { 2-oxoglutarate dehydrogenase complex }\end{array}$ & $49306 / 42289$ & $5.70 / 5.96$ & 22 & \\
\hline
\end{tabular}

Proteins shared by the liver and kidney mitochondria that are not found in heart mitochondria

$\begin{array}{lllllll}41 & \text { gi|15488606 } & \text { catalase } & 60013 / 60913 & 7.72 / 7.30-8.27 & 16 & \text { LFAYPDTHR }\end{array}$


(Continued)

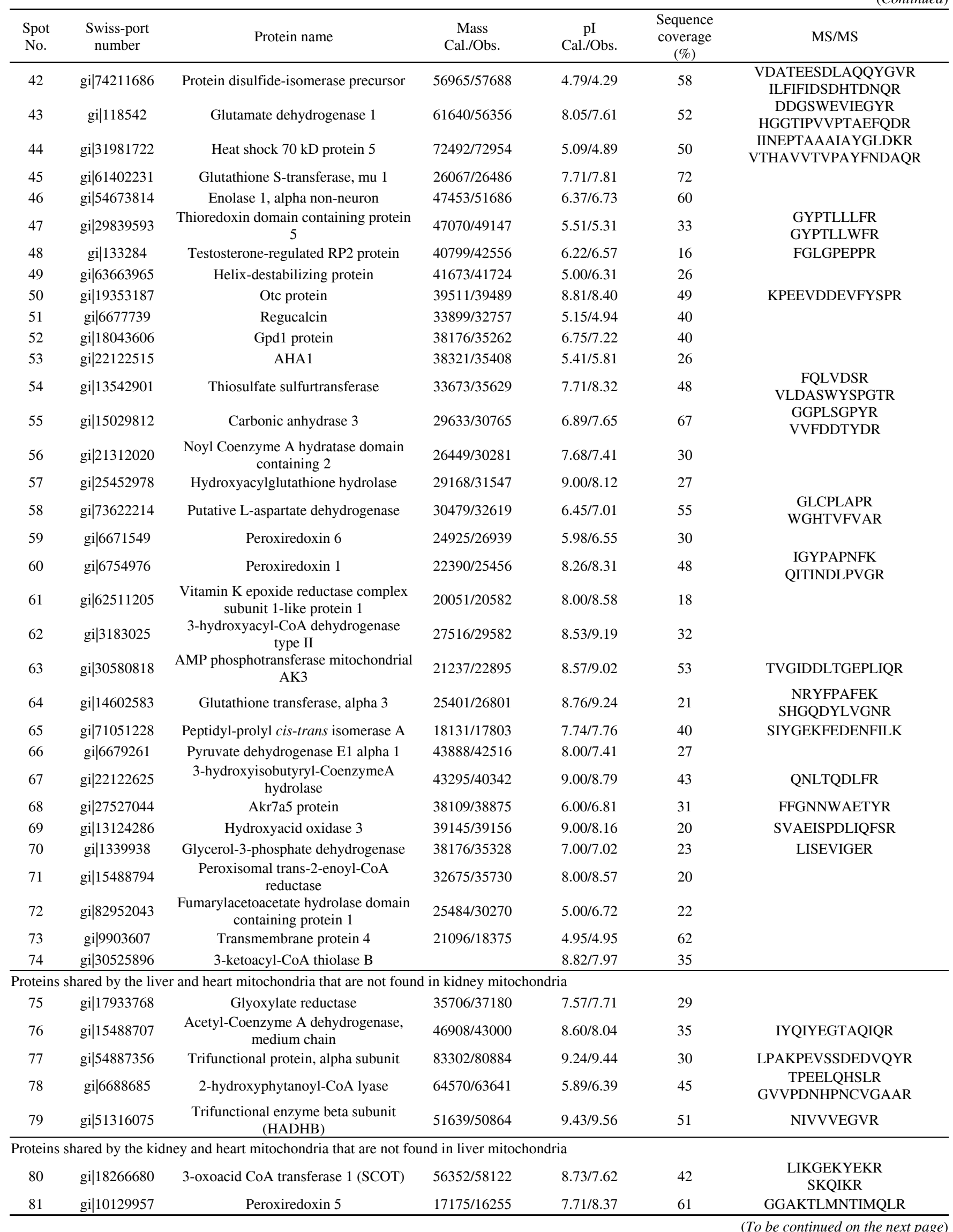




\begin{tabular}{|c|c|c|c|c|c|c|}
\hline $\begin{array}{l}\text { Spot } \\
\text { No. }\end{array}$ & $\begin{array}{l}\text { Swiss-port } \\
\text { number }\end{array}$ & Protein name & $\begin{array}{c}\text { Mass } \\
\text { Cal./Obs. }\end{array}$ & $\begin{array}{c}\mathrm{pI} \\
\text { Cal./Obs. }\end{array}$ & $\begin{array}{c}\text { Sequence } \\
\text { coverage } \\
(\%)\end{array}$ & MS/MS \\
\hline 83 & gi|29612662 & $\begin{array}{l}\text { AU RNA-binding enoyl-coenzyme A } \\
\text { hydratase }\end{array}$ & $33602 / 33764$ & $9.49 / 9.25$ & 14 & \\
\hline 84 & Q9CQ62 & 2, 4-dienoyl-CoA reductase & $36476 / 33076$ & $9.00 / 9.06$ & 13 & \\
\hline 86 & gi|29436756 & Nuclear mitotic apparatus protein 1 & $236599 / 29753$ & $5.68 / 5.83$ & 10 & \\
\hline 87 & gi|6753530 & Crystallin, alpha B & $20056 / 22708$ & $7.71 / 7.36$ & 48 & QDEHGFISR \\
\hline
\end{tabular}

\subsection{Further identification of the tissue-specific mito- chondrial proteins using an ICPL approach}

Although 2DE images provide the solid evidence that the mouse tissues have specific mitochondrial proteins, the image analysis approach is semi-quantitative. We thus adopted stable-isotope labeling to further verify the differential quantification of the 2DE spots. As described in Materials and methods, the mitochondrial proteins from three tissues were labeled with ${ }^{12} \mathrm{C}$ or ${ }^{13} \mathrm{C}$, and the paired samples were mixed with equal amounts of proteins, such as heart/kidney, heart/liver and kidney/liver. These samples were applied to 2DE. The 2DE images with labeled proteins are shown in Figure 2A, in which all the 2DE spots exhibit an acidic-shift, indicating that the mitochondrial proteins have been successfully labeled with ICPL. A typical quantitative determination based on the MALDI TOF/TOF MS mass spectrograms is presented in Figures 2B. This example indicates that SCOT is identified in the mixture of mitochondrial samples from heart and kidney with relative average abundances of 2.9:1 $(\mathrm{H}: \mathrm{K})$. The relative abundances of several different proteins identified are summarized in Table 2. Clearly, the conclusions drawn from ICPL quantification are in agreement with the 2DE image analysis results.

\subsection{Verification of the tissue-specific localization of mitochondrial proteins by Western blot analysis}

By carefully selecting antibodies which represent tissuespecificity, we implemented Western blot analysis to verify the proteomic results. As summarized in Table 1, SCP2 is specifically localized in the liver mitochondria, PDZK1 only in the kidney mitochondria, and sMtCK only in the heart mitochondria. HADHB is shared by the heart and liver mitochondria but is not found in those of the kidney, whereas SCOT is shared by the heart and kidney but is not found in the liver, and catalase is shared by the liver and kidney but is not found in the heart. As shown in Figure 3, the image data of the western blot analysis supports the conclusions derived from the proteomic observations.

\subsection{Comparison of the gene expression status for the tissue-specific mitochondrial proteins in three tissues}

All the tissue-specifically mitochondrial proteins were iden- tified to be nucleus-encoded. These proteins are synthesized and packaged outside of the mitochondria, and then enter mitochondria through a mitochondrial transporter. Because the proteins are specifically localized in the tissue mitochondria, a question is raised about whether the transcription of these proteins is also tissue specific.

We selected six tissue-specific mitochondrial proteins, sMtCK, SCP2, PDZK1, catalase, SCOT and HADHB, and examined their gene expression status in the three tissues using real-time RT-PCR. The quantitative data of RT-PCR, presented in Figure 4 with GAPDH as an internal control, revealed that the mRNA tissue-distributions for sMtCK, catalase, SCP2 and SCOT genes are similar to their proteins in terms of the tissue-specific mitochondrial location. However, PDZK1 and HADHB are widely expressed through all three tissues. The results prompted us to pursue another question on whether the status of protein expression is tissue-specific.

We used the six antibodies against sMtCK, SCP2, PDZK1, catalase, SCOT or HADHB in Western blot analyses to identify their protein abundances in mitochondria, the cytoplasm or whole tissue. As presented in Figure 3, the tissue specificity of sMtCK, catalase, SCP2, and SCOT in the cytoplasm and whole tissue is similar to their mitochondrial location, whereas the PDZK1 and HADHB levels in the cytoplasm and whole tissue is different from their distribution in the tissue-specific mitochondria. The PDZK1 protein is only detected in the kidney mitochondria, whereas this protein was found in the cytoplasm of the three tissues. The HADHB protein is detected in the liver and heart mitochondria but is not detected in those of the kidney, whereas this protein was found in all three tissues either in the cytoplasm or in the tissue extraction, even though the abundant distribution is still tissue-dependent. Taken together, the transcription and translation level for the tissue-specific mitochondrial proteins is likely to be consistently distributed in the three tissues.

\subsection{Detection of the tissue-specific mitochondrial pro- teins in vivo}

Three cell lines, Chang, $\mathrm{MC}$, and $\mathrm{H} 9 \mathrm{c} 2$, which represent the predominant cells found in the liver, kidney and heart, respectively, were selected and the subcellular distribution of the tissue-specific mitochondrial proteins were monitored 
A
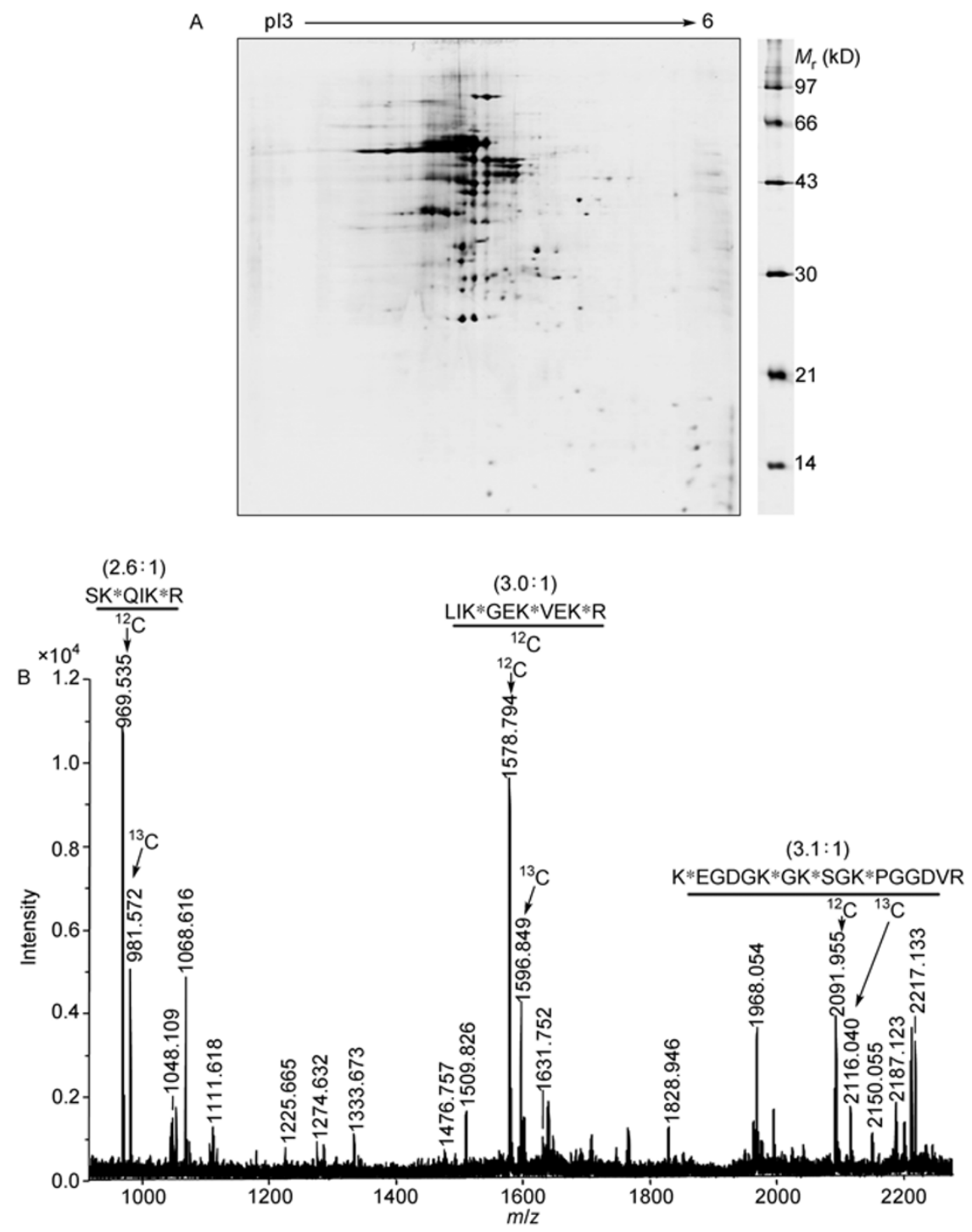

Figure 2 Quantification of the tissue-specific mitochondrial proteins by the ICPL method. A, Typical 2DE images for the heart mitochondrial proteins that are ${ }^{12} \mathrm{C}$-labeled and mixed with the kidney mitochondrial proteins which are ${ }^{13} \mathrm{C}$-labeled. B, The mass spectrum of PMF for SCOT labeled with ICPL for the mixture of heart and kidney mitochondrial proteins. Three peptide pairs 969.535/981.572, 1578.794/1596.849 and 2091.955/2116.040 were selected for the quantification calculation. The intensity ratios are illustrated in the insets.

Table 2 Quantification of the tissue-specific mitochondrial proteins by the ICPL method ${ }^{\text {a) }}$

\begin{tabular}{|c|c|c|c|c|c|c|}
\hline Protein name & Description & $\begin{array}{c}\text { Mix gel name } \\
\text { of the identified pro- } \\
\text { teins }\end{array}$ & Identified peptide with ICPL & Spectrum & Distance & Area ratio \\
\hline Catalase & $\begin{array}{c}\text { Expressed in liver } \\
\text { and kidney mito- } \\
\text { chondria, not in heart }\end{array}$ & $\begin{array}{l}\text { Identified in } \mathrm{K} / \mathrm{L}, \mathrm{H} / \mathrm{K} \text {, } \\
\mathrm{H} / \mathrm{L}\end{array}$ & $\begin{array}{c}\text { L:K } \\
\text { TFYTKVLNEEER } \\
\text { DAILFPSFIHSQKR } \\
\end{array}$ & $\begin{array}{l}1633.822 / 1639.854 \\
1763.956 / 1769.981\end{array}$ & $\begin{array}{l}6 \\
6\end{array}$ & $\begin{array}{l}1.928 \\
1.948\end{array}$ \\
\hline SCOT & $\begin{array}{l}\text { Expressed in kidney } \\
\text { and heart mitochon- } \\
\text { dria, not in liver }\end{array}$ & $\begin{array}{l}\text { Identified in } H / K, H / L \\
K / L\end{array}$ & $\begin{array}{c}\mathrm{K}: \mathrm{H} \\
\text { SKQIKR } \\
\text { LIKGEKYEKR } \\
\text { KEGDGKGKSGKPGGDVR }\end{array}$ & $\begin{array}{c}969.535 / 981.572 \\
1578.794 / 1596.849 \\
2091.955 / 2116.04\end{array}$ & $\begin{array}{l}12 \\
18 \\
24\end{array}$ & $\begin{array}{l}0.392 \\
0.331 \\
0.324\end{array}$ \\
\hline \multirow[t]{2}{*}{ HADHB } & \multirow[t]{2}{*}{$\begin{array}{l}\text { Expressed in liver } \\
\text { and heart mitochon- } \\
\text { dria, not in kidney }\end{array}$} & \multirow[t]{2}{*}{$\begin{array}{c}\text { Identified in } \mathrm{H} / \mathrm{K}, \mathrm{K} / \mathrm{L} \text {, } \\
\text { not detected in } \mathrm{H} / \mathrm{L}\end{array}$} & $\begin{array}{c}\text { K:H } \\
\text { LSLLSKFR } \\
\text { ALAMGYKPKAYLR } \\
\text { IPFLLSGTSYKDLMPHDLAR }\end{array}$ & $\begin{array}{l}1068.672 / 1074.692 \\
1691.889 / 1703.888 \\
2379.223 / 2385.236\end{array}$ & $\begin{array}{c}6 \\
12 \\
6\end{array}$ & $\begin{array}{l}0.115 \\
0.177 \\
0.143\end{array}$ \\
\hline & & & $\begin{array}{c}\mathrm{K}: \mathrm{L} \\
\text { LSLLSKFR }\end{array}$ & $1068.621 / 1074.642$ & 6 & 0.089 \\
\hline
\end{tabular}

a) L, K, H represent liver, kidney and heart mitochondria, respectively. K:L, H:K, H:L represent the image of two mitochondrial protein mixtures of two mouse tissues using ${ }^{12} \mathrm{C} /{ }^{13} \mathrm{C}$ labeling. 

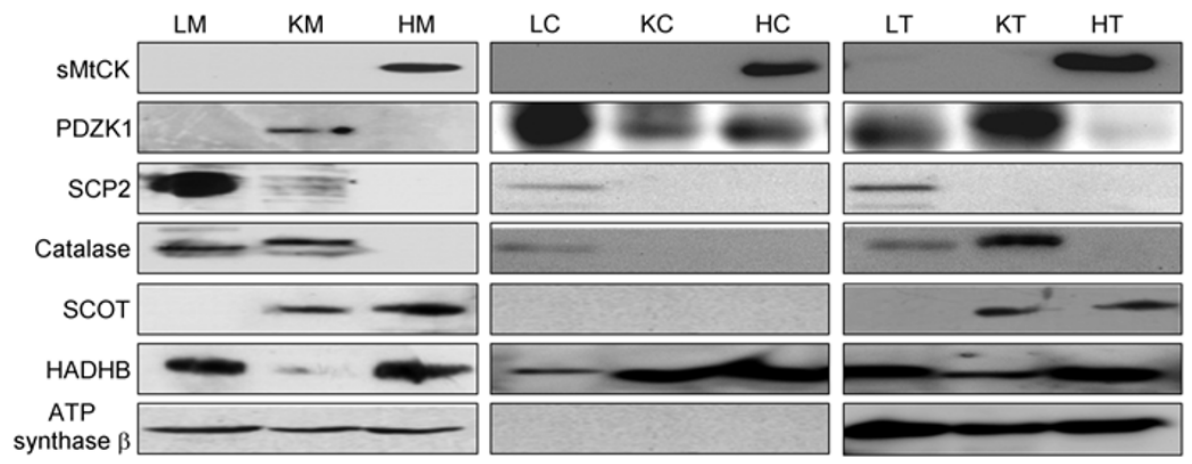

Figure 3 Analysis of Western blot results for six proteins that reside in the cytoplasm, mitochondria and tissue lysates of mouse liver, kidney and heart. The labels, LM, KM, HM, LC, KC, HC, LT, KT and HT, where L, K and H represent liver, kidney, heart and M, C and T represent mitochondria, cytoplasm and tissue lysate. The antibody against ATP synthase $\beta$ was used as a reference mitochondrial protein.
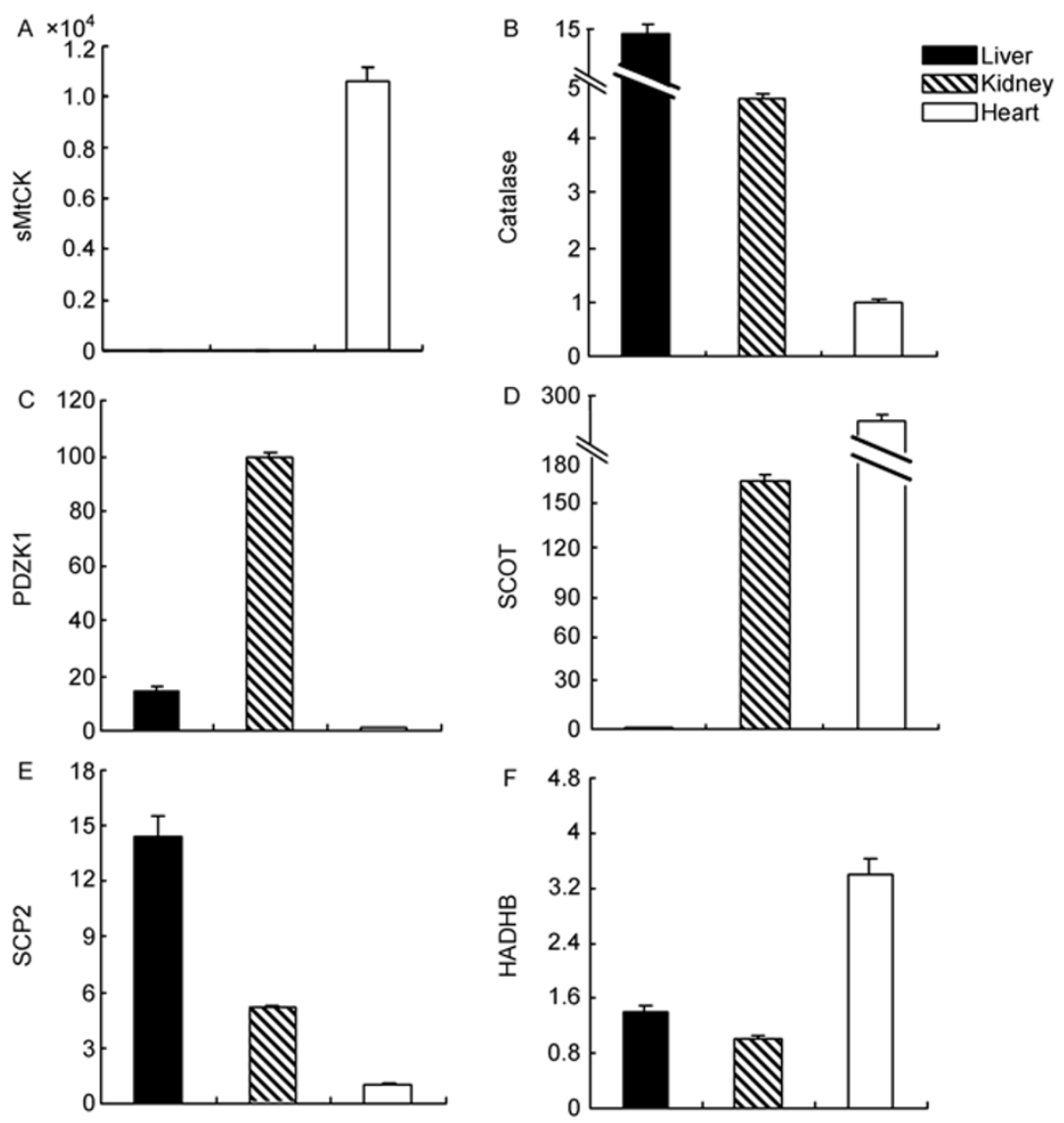

Figure 4 mRNA abundance of sMtCK, PDZK1, SCP2, catalase, SCOT, and HADHB in mouse liver, kidney and heart measured by quantitative real-time RT-PCR. The Ct values were normalized by the Ct value of GAPDH. The relative mRNA abundances were derived from the $2^{-\Delta \Delta C t}$ method.

in vivo. Representative images of the confocal microscopy are present in Figure 5, in which the tissue-specific mitochondrial proteins are recognized by the corresponding antibodies and mitochondria are labeled by MitoTracker Red. On the left panel of Figure 5, sMtCK, PDZK1 and SCP2 are specifically located in the cellular mitochondria, heart, kidney and liver, respectively, and the antibody signals precisely match with the mitochondrial indicator. On the right panel of Figure 5, catalase is present in the liver and kidney cellular mitochondria but not in those of the heart cells; SCOT was observed to be present in the heart and kidney cellular mitochondria, but was not present in those of the liver cells; and HADHB was present in the heart and liver cellular mitochondria, but not in those of the kidney cells. All the co-localization evidences of the antibodies and MitoTracker acquired from the in vivo study are in agreement 


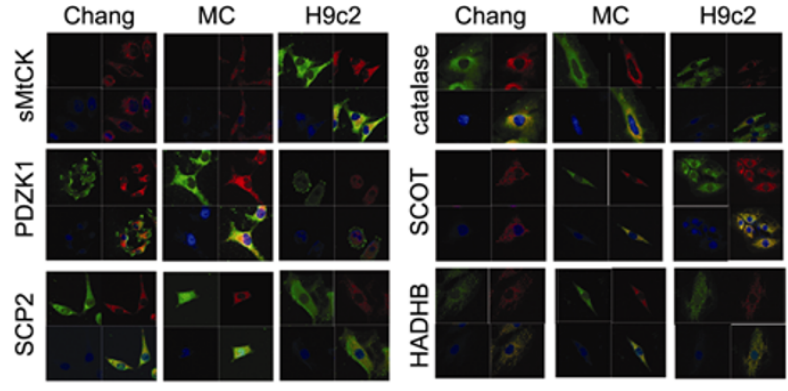

Figure 5 Confocal images for the tissue-specific mitochondrial proteins. The images of confocal microscopy for three cell lines, Chang, MC and H9c2 using six antibodies, sMtCK, PDZK1, SCP2, catalase, SCOT and $\mathrm{HADHB}$, as the primary antibodies. Mitotracker was used as the mitochondrial indictor and IgG conjugated with FITC as the secondary antibody.

with the conclusions drawn from the proteomic and immuno-blot observations. Moreover, the confocal data demonstrated that the organelle distribution of the tissue-specific mitochondrial proteins in cells is similar to their organelle distribution in tissues.

\section{Discussion}

Tissue-specific mitochondrial proteins have been documented by several laboratories; however, most early reports did not focus on the issue of whether the tissue-specific organelle is a common phenomenon found in nature. Mann's group initiated the proteomic investigation towards differential expression of proteins in tissues using LC MS/MS and found several tissue-specific mitochondrial proteins $[13,14]$; however, their major focus was to establish the methodology instead of the biological significance. In this study, our goal differs from other studies. For the first time, we clearly state that the objective is to systematically scrutinize the tissue-specific mitochondrial proteome and elucidate the natural phenomenon of protein distributions associated with tissues as well as organelles. For this systematic study to be successful, we have implemented a set of experiments based on the following considerations. First, the core data for discovery of the tissue-specific protein expression levels involves the quantitative comparison of the mitochondrial proteome in different tissues. Multiple quantifications of proteins were thus employed in this project. Secondly, since most mitochondrial proteins are encoded by nuclear genes, a mitochondrial protein may also exist outside the mitochondrion. Therefore, subcellular localization of the protein should be carefully evaluated with respect to the abundance of the protein inside and outside mitochondria. To define the correlation between transcription and translation, the determination of mRNA and protein for a tissue-specific mitochondrial protein is likely to provide further information. Third, most investigations in this field have only focused on differential proteomics in tissues. This approach cannot avoid some misinterpretations from the tissue proteomics due to the abundance of proteins contributed from multiple cells. The proteomic survey based upon the comparison of tissue and cell proteomes is therefore expected to offer more convincing evidence.

A total of 87 tissue-specific mitochondrial proteins were identified in this study. Approximate $60 \%$ of these proteins are reported in literature or found in the MITOP2 database. Additionally, some proteins were found to be localized both in the mitochondria and other subcellular organelles. For instance, 3-ketoacyl-CoA thiolase A and testosterone-regulated RP2 may be localized to both mitochondria and the peroxisome, while aldehyde dehydrogenase 3 may be localized to both mitochondria and the endoplasmic reticulum. Importantly, $10 \%$ of these mitochondrial proteins have not been previously reported as mitochondrial proteins, such as PDZK1, Glutathione S-transferase mu1 and P1. Furthermore, careful comparison of data with Mann's report was also performed. Of the 87 unique tissue-specific mitochondrial proteins found, 12 have also been documented in this report, including three in the liver; sterol carrier protein 2, glutathione S-transferase P1 and hydroxymethylglutarylCoA synthase, one in the heart; sarcomeric mitochondrial creatine kinase, seven shared by the liver and kidney; glutamate dehydrogenase 1, glutathione S-transferase mu1, 2,3-hydroxyacyl-CoA dehydrogenase II, glutathione transferase, alpha3, 3-hydroxyisobutyryl-coenzyme A hydrolase and hydroxyacid oxidase 3 , and two shared by the liver and heart; acetyl-coenzyme A dehydrogenase and the trifunctional enzyme beta subunit. However, the remaining 75 proteins were not listed in the results of Mann's group as mitochondrial proteins. These results demonstrate that the two approaches to protein identification, peptides separated by HPLC and intact proteins separated by $2 \mathrm{DE}$, have some special separate features that are not congruent. Therefore, our data complements other investigations that have used different approaches to examine mitochondrial proteins.

To further explore the tissue-specific mitochondrial proteins, we selected six proteins, sMtCK, SCP2, PDZK1, catalase, SCOT and HADHB, and examined their organelle localization through multiple approaches. Our selection of the mitochondrial biomarkers came from three criteria, (i) some proteins are well documented mitochondrial proteins, (ii) some have only been identified in this study, and (iii) technically they are measurable by the approaches employed.

sMtCK is a sarcomeric mitochondrial creatine kinase that catalyzes phosphoryl transfer reactions between creatine and ATP. This protein was found in higher abundance in heart mitochondria when compared with the other two tissues examined. This observation is not surprising because the presence of the sarcomere is unique in muscle and heart tissues $[16,17]$. The data is also in agreement with the report from Mann's group [13]. Comparison of the SCP2 abundance in three mitochondria, it was found higher level in liver. SCP2 functions in the regulation of cholesterol me- 
tabolism and transportation, and the synthesis of steroid hormones [18]. Because the synthesis of cholesterol occurs in the peroxisome and the cytosolic portion of the endoplasmic reticulum, whereas the synthesis of steroid hormones occurs in mitochondria, SCP2 is highly expressed in organs involved in lipid metabolism, and therefore expected to have different subcellular localizations $[19,20]$. Using the immunofluorescence EM technique, Keller et al. [21] found that SCP2 was localized to the mitochondria, peroxisome, and endoplasmic reticulum in rat liver tissue. Moncecchi et al. [22] proposed that the multiple subcellular localization of SCP2 may be due to SCP2 isomers that are generated by different RNA transcription, editing and post-translational modification processes. Our data acquired from 2DE, western blot and real-time PCR matches with the theoretical expectation as well as previous reports: the $S C P 2$ gene is primarily expressed in the liver. Although the results of the confocal analysis indicate that SCP2 is localized in mitochondria, our data cannot exclude the possibility that SCP2 is localized in other organelle due to the lack of evidence obtained from the specific indicators for other organelles. PDZK1 is mainly responsible for the regulation of $\mathrm{Na}^{+} / \mathrm{H}^{+}$ exchange so that this protein is highly expressed in kidney tissue, such as the surface of the renal tubular epithelial cells [23-26]. The subcellular localization of PDZK1 has not been reported yet. In our data, the gene expression of PDZK1 was detectable in mouse liver, kidney and heart, by real-time PCR or by protein identification. Interestingly, PDZK1 was only found in the kidney mitochondria but not in those of the other two tissues, whereas this protein was detected in the cytoplasm of all three tissues. The specific localization of PDZK1 in the kidney mitochondria evokes a hypothesis that PDZK1 is likely to have dual functions which are determined based on the specific cellular location of the protein.

Catalase is one of the major antioxidases in organisms, and widely expressed in many mammalian tissues. Generally, catalase is believed to be localized in the peroxisome and cytosol. With quantitatively proteomic approaches, Jiang et al. [27] claimed that catalase was localized to rat liver mitochondria. Our data supports this observation and further extends the previous analysis on this protein to indicate that catalase is present in liver and kidney mitochondria but not in heart mitochondria. The catalase levels, either mRNA or protein, in the three tissue mitochondria were observed to be proportional to its abundance in the cytoplasm of the three tissues. The expression of catalase was found to be the lowest in both the cytoplasm and mitochondria in all three tissues. Therefore, the organelle localization for catalase is likely to be dependent on the gene expression levels in the tissues or cells, and unlikely to be solely dependent on the organelle favorability. HADHB has been recognized to form part of an enzyme complex called the mitochondrial trifunctional protein and participates in the breakdown of long-chain fatty acids in mitochondria [28].
Uchida et al. [29] pointed out that this protein is localized to the mitochondrial matrix. HADHB is expressed in many tissues such as liver, muscle and retina. In the results described above, HADHB, either mRNA or protein, was detected in all three tissues; however, the levels in the liver and heart tissue were higher than observed in the kidney. An important point is that HADHB was detected in the heart and liver mitochondria but not in the kidney mitochondria, whereas this protein is widely distributed in the cytoplasm of all three tissues. Moreover, HADHB mRNA and protein levels are not low in the kidney tissue and cytoplasm when compared with the other two tissues. Hence, this observation questions how the mitochondrial trifunctional protein functions in kidney mitochondria, or the function of HADHB is not fully understood. SCOT is a mitochondrial matrix homodimer that was first identified in pig hearts and sheep kidneys [30,31]. SCOT catalyzes the reversible transfer of a CoA moiety from succinyl CoA to the ketone body acetoacetate [32]. The tissue levels of SCOT activity correlate well with the ketolytic capacity. The transcriptomic and proteomic data above reveal that SCOT was undetectable in the liver, cell lysate or mitochondria. This observation is not unexpected because the liver normally lacks the enzymes that efficiently utilize ketone bodies, and synthesized ketone bodies in the liver diffuse into the blood where they are transported to other tissues for metabolism. SCOT in the heart and kidney mitochondria is thus capable of metabolizing ketone bodies in the circulatory system.

In summary, we have integrated multiple approaches to systematically analyze proteins that are localized in particular cellular organelles, and based on the observations of this study propose the term tissue-specific mitochondrial proteins. Although the mechanisms of how tissue-specific mitochondrial proteins are generated have yet to be revealed, these proteins are likely to play an important role in diversifying the functions of mitochondria located in different tissues. Understanding the tissue specific mitochondrial components will be important in fully understanding mitochondrial physiology and pathology.

This work was supported by the National Natural Science Foundation of China (Grant No. 30700378) and National High Technology Research and Development Program of China (Grant No. 2006AA02A308).

1 Hockenbery D M, Oltvai Z N, Yin X M, et al. Bcl-2 functions in an antioxidant pathway to prevent apoptosis. Cell, 1993, 75: 241-251

2 Kluck R M, Bossy-Wetzel E, Green D R, et al. The release of cytochrome $\mathrm{c}$ from mitochondria: a primary site for Bcl-2 regulation of apoptosis. Science, 1997, 275: 1132-1136

3 Terkeltaub R, Johnson K, Murphy A, et al. Invited review: The mitochondrion in osteoarthritis. Mitochondrion, 2002, 1: 301-319

4 Wallace D C. Mitochondrial diseases in man and mouse. Science, 1999, 283: 1482-1488

5 Andersson S G, Zomorodipour A, Andersson J O, et al. The genome sequence of Rickettsia prowazekii and the origin of mitochondria. Nature, 1998, 396: 133-140

6 Thorburn D R. Diverse powerhouses. Nat Genet, 2004, 36: 13-14 
7 Shuman S K. A physician's guide to coordinating oral health and primary care. Geriatrics, 1990, 45: 47-51, 54, 57

8 Fawcett D W, Doxsey S, Buscher G. Salivary gland of the tick vector (R. appendiculatus) of East Coast fever. I. Ultrastructure of the type III acinus. Tissue Cell, 1981, 13: 209-230

9 Fawcett D W, Doxsey S, Buscher G. Salivary gland of the tick vector (R. appendiculatus) of East Coast fever. II. Cellular basis for fluid secretion in the type III acinus. Tissue Cell, 1981, 13: 231-253

10 Vayssiere J L, Cordeau L, Larcher J C, et al. Tissue-specific mitochondrial proteins. Biochimie, 1989, 71: 787-791

11 Watmough N J, Bindoff L A, Birch-Machin M A, et al. Impaired mitochondrial beta-oxidation in a patient with an abnormality of the respiratory chain. Studies in skeletal muscle mitochondria. J Clin Invest, 1990, 85: 177-184

12 Reichert A S, Neupert W. Mitochondriomics or what makes us breathe. Trends Genet, 2004, 20: 555-562

13 Mootha V K, Bunkenborg J, Olsen J V, et al. Integrated analysis of protein composition, tissue diversity, and gene regulation in mouse mitochondria. Cell, 2003, 115: 629-640

14 Forner F, Foster L J, Campanaro S, et al. Quantitative proteomic comparison of rat mitochondria from muscle, heart, and liver. Mol Cell Proteomics, 2006, 5: 608-619

15 Kislinger T, Cox B, Kannan A, et al. Global survey of organ and organelle protein expression in mouse: combined proteomic and transcriptomic profiling. Cell, 2006, 125: 173-186

16 Payne R M, Haas R C, Strauss A W. Structural characterization and tissue-specific expression of the mRNAs encoding isoenzymes from two rat mitochondrial creatine kinase genes. Biochim Biophys Acta, 1991, 1089: 352-361

17 Payne R M, Strauss A W. Expression of the mitochondrial creatine kinase genes. Mol Cell Biochem, 1994, 133/134: 235-243

18 Baum C L, Kansal S, Davidson N O. Regulation of sterol carrier protein-2 gene expression in rat liver and small intestine. J Lipid Res, 1993, 34: 729-739

19 Chesterton C J. Distribution of cholesterol precursors and other lipids among rat liver intracellular structures. J Biol Chem, 1968, 243: 1147-1151

20 Reinhart M P, Billheimer J T, Faust J R, et al. Subcellular localization of the enzymes of cholesterol biosynthesis and metabolism in rat liver. J Biol Chem, 1987, 262: 9649-9655
21 Keller G A, Scallen T J, Clarke D, et al. Subcellular localization of sterol carrier protein-2 in rat hepatocytes: its primary localization to peroxisomes. J Cell Biol, 1989, 108: 1353-1361

22 Moncecchi D, Pastuszyn A, Scallen T J. cDNA sequence and bacterial expression of mouse liver sterol carrier protein-2. J Biol Chem, 1991, 266: 9885-9892

23 Gisler S M, Stagljar I, Traebert M, et al. Interaction of the type IIa $\mathrm{Na} / \mathrm{Pi}$ cotransporter with PDZ proteins. J Biol Chem, 2001, 276: 9206-9213

24 Reczek D, Berryman M, Bretscher A. Identification of EBP50: A PDZ-containing phosphoprotein that associates with members of the ezrin-radixin-moesin family. J Cell Biol, 1997, 139: 169-179

25 Wang S, Yue H, Derin R B, et al. Accessory protein facilitated CFTR-CFTR interaction, a molecular mechanism to potentiate the chloride channel activity. Cell, 2000, 103: 169-179

26 Yun C H, Oh S, Zizak M, et al. cAMP-mediated inhibition of the epithelial brush border $\mathrm{Na}^{+} / \mathrm{H}^{+}$exchanger, NHE3, requires an associated regulatory protein. Proc Natl Acad Sci USA, 1997, 94: 3010-3015

27 Jiang X S, Dai J, Sheng Q H, et al. A comparative proteomic strategy for subcellular proteome research: ICAT approach coupled with bioinformatics prediction to ascertain rat liver mitochondrial proteins and indication of mitochondrial localization for catalase. Mol Cell Proteomics, 2005, 4: 12-34

28 Eaton S, Bursby T, Middleton B, et al. The mitochondrial trifunctional protein: Centre of a beta-oxidation metabolon? Biochem Soc Trans, 2000, 28: 177-182

29 Uchida Y, Izai K, Orii T, et al. Novel fatty acid beta-oxidation enzymes in rat liver mitochondria. II. Purification and properties of enoyl-coenzyme A (CoA) hydratase/3-hydroxyacyl-CoA dehydrogenase/3-ketoacyl-CoA thiolase trifunctional protein. J Biol Chem, 1992, 267: 1034-1041

30 Bateman K S, Brownie E R, Wolodko W T, et al. Structure of the mammalian CoA transferase from pig heart. Biochemistry, 2002, 41: 14455-14462

31 Rangarajan E S, Li Y, Ajamian E, et al. Crystallographic trapping of the glutamyl-CoA thioester intermediate of family I CoA transferases. J Biol Chem, 2005, 280: 42919-42928

32 Hersh L B, Jencks W P. Isolation of an enzyme-coenzyme A intermediate from succinyl coenzyme A-acetoacetate coenzyme A transferase. J Biol Chem, 1967, 242: 339-340

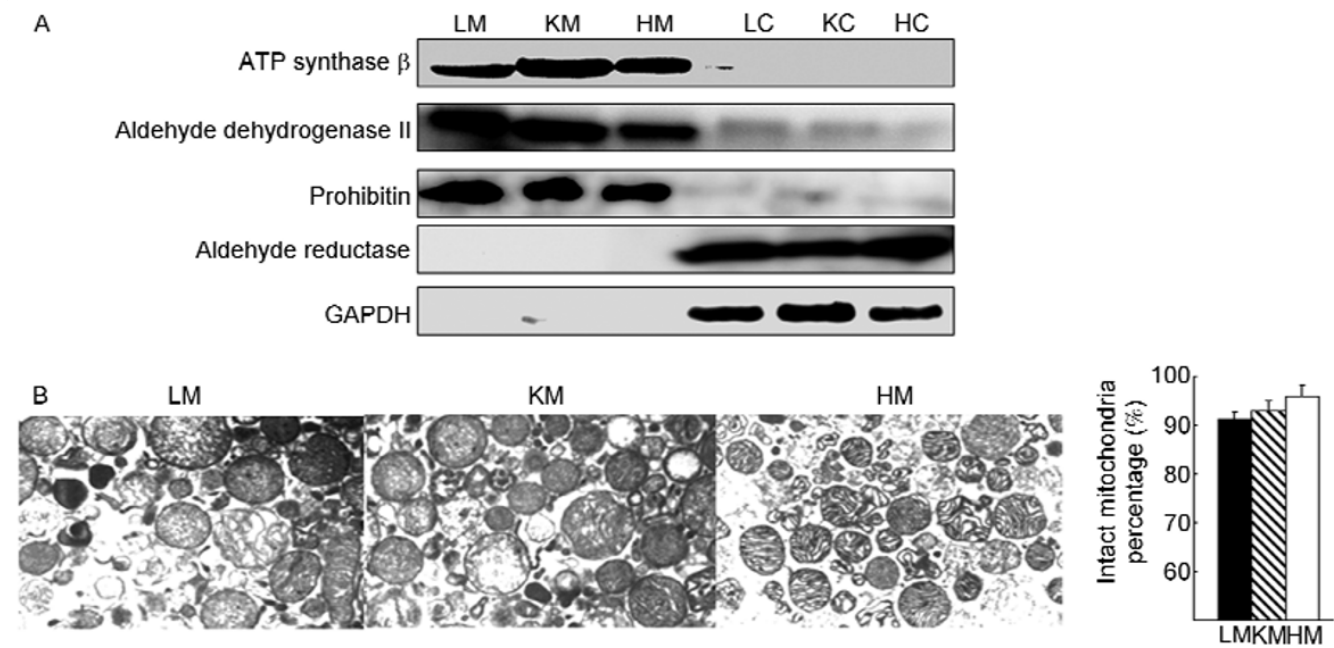

Supplemental Figure 1 Confirmation of mitochondrial purity and integrity. A, Western blot was used to check the mitochondrial characterizations using antibodies of ATP synthase $\beta$, aldehyde dehydrogenase II, and Prohibitin as the mitochondrial biomarker, and antibodies of Aldehyde reductase and GAPDH as the cytoplasm biomarker. B, TEM images of mitochondrial preparations from liver, kidney and heart. The magnification of the TEM images was 20000x. The ratios of intact mitochondria were calculated the intact mitochondria number of the whole views in the three parallel preparations. And the intact mitochondria percentage in liver, kidney and heart was depicted in the scale bar.

Open Access This article is distributed under the terms of the Creative Commons Attribution License which permits any use, distribution, and reproduction in any medium, provided the original author(s) and source are credited. 